\title{
HPLC analysis of phenolic compounds in leaves and inflorescences of Sorbaria pallasii
}

\author{
Vera A. Kostikova ${ }^{1 *}$, and Tatiana N. Veklich ${ }^{2}$ \\ ${ }^{1}$ Central Siberian Botanical Garden, SB RAS, Zolotodolinskaya Str., 101, Novosibirsk 630090, \\ Russia \\ ${ }^{2}$ Amur Branch of Botanical Garden Institute, FEB RAS, Ignatievskoe Road, 2 km, Blagoveshchensk \\ 675000, Russia
}

\begin{abstract}
At least 22 phenolic compounds were identified in aqueousethanol extracts from Sorbaria pallasii (G. Don fil.) Pojark. leaves and at least 28 in its inflorescences by High-Performance Liquid Chromatography. Two acids (chlorogenic and $p$-hydroxybenzoic) and five flavonols (hyperoside, isoquercitrin, quercitrin, kaempferol, and astragalin) were identified among them. Flavonoid aglycones were obtained from the leaves and inflorescences by hydrochloric-acid hydrolysis of the aqueous-ethanol extracts (1:1). Three flavonol aglycones (quercetin, kaempferol, and isorhamnetin) were identified in the extract hydrolysates from $S$. pallasii above-ground organs through chromatographic analysis. Additionally, a flavone aglycone (luteolin) was found in the extract hydrolysates from the leaves. Kaempferol glycosides are predominant phenolic compounds in $S$. pallasii inflorescences, and quercetin glycosides in its leaves.
\end{abstract}

\section{Introduction}

The search for new sources of bioactive substances of plant origin is relevant at present. Phenolic compounds (PCs) are secondary metabolites discovered in most plant tissues. They have a wide range of pharmacological and beneficial health effects for humans, including, among others, antiallergic, antifungal, antioxidant, and anti-inflammatory properties [1].

Sorbaria pallasii (G. Don fil.) Pojark. (= S. grandiflora (Sweet) Maxim.), is a $\leq 50-\mathrm{cm}-$ high shrub that belongs to the Spiraeoideae Agardh subfamily of the Rosaceae Juss. family. This plant grows in Eastern Siberia and in the Russian Far East on rocky slopes and placers, alpine lawns, and in rocky lichen tundra [2]. There are no literature data on biological activities of its components or on the profile and levels of active ingredients of S. pallasii. It has been found, however, that another member of the genus Sorbaria - S. sorbifolia (L.) A. Br., grown in Russia, Mongolia, Japan, and China - can improve rheological properties of blood, resolve stasis, decrease swelling, and alleviate pain and has been used for the treatment of bone fractures, bruises, and rheumatic arthritis in Traditional Chinese Medicine via oral and topical administration [3]. An ethyl-acetate extract of above-ground parts of $S$. sorbifolia has immunomodulatory properties and enhances the anticancer action

* Corresponding author: serebryakova-va@yandex.ru 
of chemotherapeutic drugs against entangling carcinoma 180 [4]. A decoction of $S$. sorbifolia is used against diarrhoea and rheumatoid arthritis in Amur Oblast and Transbaikalia. This plant is indicated for tuberculosis of the skin and other skin diseases [5]. Anti-inflammatory, antimicrobial, antimelanogenic, and antioxidant properties of extracts from Sorbaria representatives have been reported by researchers abroad [6-9]. Their previous research into Sorbaria phytochemistry has led to the isolation of such triterpenoids as cucurbitacin [10], flavonoids, phenol carboxylic acids, cyanoglycosides, chromone derivatives $[8,11,12]$, and triterpene acids of ursanoic and oleanic series [13].

The aims of the present study were qualitative and quantitative analyses of PCs in aqueous-ethanol extracts from $S$. pallasii leaves and inflorescences by high-performance liquid chromatography (HPLC).

\section{Materials and methods}

PCs were analyzed in the leaves and inflorescences of $S$. pallasii. Specimens were collected in 2019 in Amur Oblast in Zeysky Nature Reserve (subalpine zone) on a rocky slope overgrown with moss. The collected parts of the plant were dried separately in the open air in a shadow. Afterwards, the dry material was shredded to $2-3 \mathrm{~mm}$ pieces and blended, and representative samples were chosen. PCs were studied in $40 \%$ aqueous-ethanol extracts obtained via extraction on a water bath.

This analysis was performed on an Agilent $1200 \mathrm{HPLC}$ system including a Zorbax SBC18 column $(5 \mu \mathrm{m}, 4.6 \times 150 \mathrm{~mm})$ and equipped with a diode array detector and a ChemStation system for the collection and processing of chromatographic data (Agilent Technology, Palo Alto, CA, USA), by the method of T.A. van Beek [14] with modifications. The separation was conducted under the following conditions: for $27 \mathrm{~min}$, a gradient from $31 \%$ to $33 \%$ of methanol acidified in phosphoric acid $(0.1 \%)$; next, in the mobile phase, the concentration of methanol in the solution of phosphoric acid $(0.1 \%)$ was changed from $33 \%$ to $46 \%$ for $11 \mathrm{~min}$, then from $46 \%$ to $56 \%$ during the next $12 \mathrm{~min}$, and from $56 \%$ to $100 \%$ during 4 min (solvent system I). The eluent flow rate was $1 \mathrm{ml} / \mathrm{min}$, column temperature was $26^{\circ} \mathrm{C}$, and sample volume $10 \mu \mathrm{l}$, and detection was conducted at wavelengths of $254,270,290,340,360$, and $370 \mathrm{~nm}$. Quantification of individual components in the plant samples was performed by an external standard method [14]. Levels of individual PCs were calculated by means of hyperoside. The samples were analyzed twice.

The analysis of free aglycones that formed after acid hydrolysis of the corresponding flavonoid glycosides was carried out due to the lack of available standard samples and difficult separation conditions [14]. To this end, $0.5 \mathrm{ml}$ of $\mathrm{HCl}(2 \mathrm{~N})$ was added to $0.5 \mathrm{ml}$ of an extract. The mixture was heated on a boiling water bath for $2 \mathrm{~h}$. Chromatographic analysis was conducted in gradient elution mode in solvent system II: i.e., in the mobile phase, methanol concentration in the aqueous solution of phosphoric acid $(0.1 \%)$ was changed from $45 \%$ to $48 \%$ during 18 min. Detection was conducted at a wavelength of 370 $\mathrm{nm}$. The content of flavonoid glycosides (glycosides of quercetin, kaempferol, isorhamnetin, and luteolin separately) in the plant samples was calculated from the level of free aglycones that formed after acid hydrolysis. Coefficients retrieved from the literature were employed to convert the aglycone concentrations to the concentrations of respective glycosides: 2.504 for quercetin, 2.588 for kaempferol, and 2.437 for isorhamnetin [14]. The calculation of concentrations of luteolin glycosides was done using the coefficient for quercetin.

\section{Results and discussion}


In the analysis of the PC profile in solvent system I, it was demonstrated that no less than 22 PCs are present in the aqueous-ethanol extracts from $S$. pallasii leaves, and at least 28 such compounds in its inflorescences (see the Fig. and Table). Two acids (chlorogenic and $p$-hydroxybenzoic) and five flavonols - quercetin glycosides (hyperoside, isoquercitrin, and quercitrin), kaempferol, and its glycoside (astragalin) - were identified by means of UV spectra and a comparison of retention times in the chromatograms with those of standard samples. Chlorogenic and $p$-hydroxybenzoic acids, hyperoside, quercitrin, and astragalin have been detected earlier in studies on the leaves and inflorescences of Sorbaria genus representatives $[8,12]$. Kaempferol and isoquercitrin were identified in $S$. pallasii for the first time. Other PCs were not identified. Their UV spectra were registered in on-line mode during the chromatography. According to their spectral characteristics, the unidentified PCs were assigned to flavanones $\left(\lambda_{\max }=275-290\right.$ and 290-330 nm), flavones $\left(\lambda_{\max }=250-270\right.$ and $210-350 \mathrm{~nm})$, flavanols $\left(\lambda_{\max }=250-270\right.$ and $\left.350-390 \mathrm{~nm}\right)$, and oxybenzoic $\left(\lambda_{\max }=\right.$ 235-270 and 290-305 nm) or hydroxycinnamic acid $\left(\lambda_{\max }=230-240\right.$ and $\left.290-320 \mathrm{~nm}\right)$ [15].

Table. Characteristics and levels of the PCs detected by HPLC in the extracts of $S$. pallasii leaves and inflorescences

\begin{tabular}{|c|c|c|c|c|c|}
\hline \multirow{2}{*}{$\begin{array}{l}\text { Peak } \\
\text { No. }\end{array}$} & \multirow{2}{*}{ Compound } & \multirow{2}{*}{$\begin{array}{c}\text { Retention } \\
\text { time }\left(t_{R}\right), \\
\min \end{array}$} & \multirow{2}{*}{$\begin{array}{c}\text { Spectral characteristic } \\
\quad\left(\lambda_{\max }, \mathrm{nm}\right)\end{array}$} & \multicolumn{2}{|c|}{$\begin{array}{l}\text { Content, } \mathrm{mg} / \mathrm{g} \text { of } \\
\text { air-dried materials }\end{array}$} \\
\hline & & & & leaves & inflorescences \\
\hline \multicolumn{6}{|c|}{ Extracts (solvent system I) } \\
\hline 1 & chlorogenic acid & 3.2 & $244,300 \mathrm{gc}, 330$ & 0.17 & 0.07 \\
\hline 2 & $p$-hydroxybenzoic acid & 4.3 & 250 & 0.50 & 0.11 \\
\hline 3 & flavanone & 10.2 & 280,325 & 4.88 & 2.40 \\
\hline 4 & hyperoside & 18.0 & $255,268 \mathrm{gc}, 355$ & 1.49 & 2.60 \\
\hline 5 & isoquercitrin & 19.4 & $259,266 \mathrm{gc}, 358$ & 1.01 & 1.80 \\
\hline 6 & flavonol & 24.5 & $255,275,355$ & 5.82 & 1.08 \\
\hline 7 & quercitrin & 30.8 & 260,330 & 1.49 & 1.70 \\
\hline 8 & astragalin & 32.5 & $265,300 \mathrm{gc}, 350$ & 0.80 & 2.11 \\
\hline 9 & flavone & 36.9 & 270,340 & 6.83 & 0.85 \\
\hline 10 & kaempferol & 47.0 & 265,365 & - & 0.17 \\
\hline \multicolumn{6}{|c|}{ Hydrolysates of extracts (solvent system II) } \\
\hline 1 & quercetin & 6.6 & 255,372 & 8.13 & 7.60 \\
\hline 2 & luteolin & 8.3 & $250,260 \mathrm{gc}, 350$ & 0.65 & - \\
\hline 3 & kaempferol & 11.1 & 265,365 & 1.90 & 9.19 \\
\hline 4 & isorhamnetin & 12.4 & 255,370 & 1.12 & 5.47 \\
\hline
\end{tabular}

Note. Each peak number in the table corresponds to a peak number in the Fig.; "_"“: compound not detected.

Hyperoside, isoquercitrin, quercitrin, flavanone $3\left(t_{R}=10.2 \mathrm{~min}\right)$, flavonol $6\left(t_{R}=24.5 \mathrm{~min}\right)$, and flavone $9\left(t_{R}=36.9 \mathrm{~min}\right)$ turned out to be the main PCs in the extracts from the leaves and inflorescences of $S$. pallasii. Aside from the said compounds, astragalin is also a major $\mathrm{PC}$ in inflorescences. Kaempferol was detected only in the inflorescence extracts. In the extracts from $S$. pallasii leaves and inflorescences, we did not find protocatechuic acid $\left(\mathrm{t}_{\mathrm{R}}=\right.$ $2.7 \mathrm{~min}$ ), which was extracted by other authors from Sorbaria plants [12].

Analysis of PC concentrations in the extracts from S. pallasii leaves and inflorescences revealed that the levels of hyperoside and isoquercitrin in the inflorescences are 1.7-fold 
higher and the level of astragalin is 2.6-fold higher than those in the leaves (see the Table). Concentrations of flavanone 3 , flavonol 6 , and flavone 9 were $\geq 2$-fold higher in the leaves than in the inflorescences. Furthermore, concentrations of the identified acids (chlorogenic and $p$-hydroxybenzoic) was higher in the leaves than in the inflorescences.

To quantify flavonoid glycosides separately, acid hydrolysis of aqueous-ethanol extracts from the leaves and inflorescences was carried out. As a result of the chromatographic analysis of $S$. pallasii leaves and inflorescences in solvent system II, three flavonol aglycones were detected: quercetin, kaempferol, and isorhamnetin. Additionally, a flavone aglycon (luteolin) was found in the leaves. Quercetin was the dominant PC in the leaves, and kaempferol in the inflorescences. During the conversion of aglycone concentrations to the corresponding glycoside concentrations, it was demonstrated that the highest total level of quercetin glycosides is present in the leaves $(8.13 \mathrm{mg} / \mathrm{g})$, and the highest total level of kaempferol glycosides $(9.19 \mathrm{mg} / \mathrm{g})$ and isorhamnetin $(5.47 \mathrm{mg} / \mathrm{g})$ is found in the inflorescences.

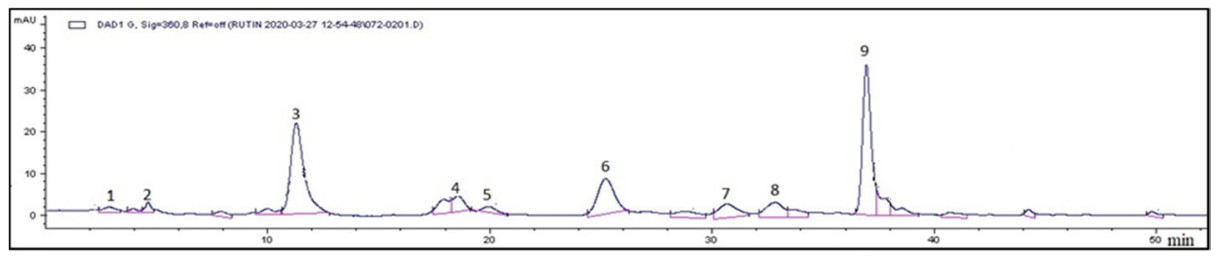

Fig. A chromatogram of the $40 \%$ aqueous-ethanol extract from S. pallasii leaves in solvent system I (detection at $360 \mathrm{~nm}$ ). On the $\mathrm{X}$-axis: retention time, min; on the Y-axis: the detector signal, in units of optical density. The peak number corresponds to the ID number of a compound in the Table.

\section{Conclusion}

Chlorogenic and $p$-hydroxybenzoic acids, hyperoside, isoquercitrin, quercitrin, astragalin, and kaempferol were identified in aqueous-ethanol extracts of $S$. pallasii leaves and inflorescences by HPLC for the first time. Quercetin, kaempferol, and isorhamnetin were detected in hydrolysates of the leaf and inflorescence extracts. Additionally, luteolin was found in the leaves. The profile and levels of PCs as well as biological activities of $S$. pallasii components require further research, which will allow to more completely determine the spectrum of useful properties of this plant.

The work was supported by a Budgetary Project of the Central Siberian Botanical Garden (the Siberian Branch of the Russian Academy of Sciences), No. AAAA-A17-117012610051-5.

\section{References}

1. G. Zengin, A. Mocan, S. Uysal, R. Ceylan, G. Crişan, A. Aktumsek, Analytical Chemistry: Developments, Applications and Challenges in Food Analysis (2017)

2. A. V. Polozhij, Flora of Siberia, 8 (Nauka, Novosibirsk, 1988)

3. The editorial committee of Chinese herbals, State Administration of Traditional Chinese Medicine, 10 (Shanghai Science and Technology Press, Shanghai (2000)

4. Z. Xuewu, Z. Yumei, G. Liping, Q. Yingchun, S. Quan, Journal of Chinese Medicinal Materials, 1 (2004)

5. Plant resources of the USSR: flowering plants, their chemical composition, use. Family Hydraginaceae - Haloragaceae (Nauka, L., 1987)

6. B. Paudel, H. D. Bhattarai, I. C. Kim, H. Lee, R. Sofronov, L. Ivanova, J. H. Yim, Biological Research, 47 (2014) 
7. F. Izhar, M. Imran, T. H. Bokhari, M. Yousaf, S. Javed, S. Rehman, L. Mitu, Rev. Chim., 70, 12 (2019)

8. G-W. Qu, C-J. Wu, S.-Z. Gong, Z-P. Xie, C-J. Lv. Fitoterapia, 111 (2016)

9. K. Nishi, M. Mori, D. Nakayama, J. Sato, I.H. Kim, M. Kim, T. Sugahara, Biomedical Dermatology, 4, 1 (2020)

10. S.-M. Lee, C.-G. Lee, Analytical Sci. and Tech., 14, 2 (2001)

11. V. G. Zaitsev, G. V. Makarova, N. F. Komissarenko, Chem. Nat. Compd., 5 (1969)

12. X. D. Li, China journal of Chinese Materia Medica, 27, 11 (2002)

13. C. $\mathrm{Wu}, \mathrm{X}$. Cui, P. Yu, M. Yang, Y. Zhang, X. Liu, G. Qu, Chem. Nat. Compd., 55(2019)

14. T.A. van Beek, P. Montoro, J. Chromatogr. A, 1216, 11 (2009)

15. M.N. Zaprometov, Phenolic compounds: distribution, metabolism and function in plants (Nauka, M., 1994) 